\section{Establishing common leadership practices and their influence on providers and service delivery in selected hospitals in Lusaka province, Zambia}

\author{
Regina M. Mulenga, Selestine Nzala, \\ Wilbroad Mutale \\ Department of Health Policy and \\ Management, School of Public Health, \\ University of Zambia, Lusaka, Zambia
}

\begin{abstract}
In an evolving health care environment, hospitals need managers with high levels of technical and professional expertise who do not only concentrate on patient care, but also go further to demonstrate good leaderin this study shows two of the factors influencing hospital performance. The first factor is the effectiveness of leaders within the hospital and secondly the dedication, motivation, commitment and performance of employees that will improve health care services.
\end{abstract} ship practices. In Zambia, the health sector's mission is "to provide equity of access to cost-effective quality health services as close to the family as possible". Only competent leadership can drive such an agenda. This study, conducted in selected $1^{\text {st }}$ level Lusaka hospitals aimed at establishing the existing common leadership practices and their influence on healthcare providers and service delivery. The study employed a cross-sectional qualitative research method design, to establish and examine the leadership practices through 10 health system managers and 32 healthcare providers. The data was obtained using in-depth interviews, focus group discussion, participant observation and document review. Data analysis was done by first transcribing audio-recorded interviews and grouping them into data sets (matrixes) where emerging themes were categorized manually. The information obtained assisted in making conclusions and interpretations by providing eminent explanations pointing to specific leadership styles and influence caused on healthcare providers and service delivery. The common leadership practices obtained in this study was the transformational leadership followed by transactional leadership while laissez-faire was rare type of leadership. This conclusion was arrived at through the practices that were pointing to transformational and transactional leadership as preferred by the leaders and perceived or experienced by providers. These practices were explained as networking, interpersonal relationships, human/material resources management, monitoring and evaluation, dictatorial tendencies and overworking of employees. Furthermore, these practices were seen to have strong influence on healthcare providers through enhanced confidence, motivation for hard work and compromised quality of care. The resultant impact on service delivery was high quality performance as well as poor performance. Leadership styles affect employees' commitment, motivation, satisfaction, extra effort and efficiency. This in turn has a bearing on performance and directly or indirectly influences patient care and its quality. Health system managers have a significant role in using leadership styles that promote good practice. It can be safely concluded that hospital performance and quality health care delivery services is a product of several factors. The analysis of leadership practices

\section{Introduction}

In an evolving health care environment, hospitals need managers with high levels of technical and professional expertise who do not only concentrate on patient care, but also go further to demonstrate good leadership practices. It has been acknowledged that promotion of most health institution managers to management positions are based on clinical expertise alone and they luck managerial capacities. ${ }^{1,2}$ Research studies has shown that leadership practices are the basis of daily interactions between leaders and healthcare providers and that the use of leadership practices may be an important indirect contributor to health care delivery outcomes. ${ }^{3,4}$ This is because the more the leadership is effective, the better the level of satisfaction among those who provide the services thereby improving the results of the health organization. ${ }^{5}$ To ensure a good supply of healthcare providers, it is important to retain them and that ability of retaining them depends on job satisfaction and motivation. For the leaders to have the capacity to adopt good leadership practices that will have the best outcome on provider's satisfaction and quality service delivery, they need to have the ability of integrating leadership and management into personal identity into which skills and knowledge are embedded. Leadership is defined by Huber ${ }^{6}$ as the process of influencing people to accomplish goals. Effective leadership is positively associated with providers' satisfaction, as well as with patient and organization outcome. ${ }^{5,7,8}$
Correspondence: Regina M. Mulenga, Emmaus Spirituality Centre, PO Box 320084 Woodlands, Lusaka, Zambia.

E-mail: mulengaregina@gmail.com

Key words: Transformational leadership, Transactional leadership, Laissaze-fare leadership, leadership practices.

Contributions: the authors contributed equally.

Conflict of interest: the authors declare no potential conflict of interest.

Funding: none.

Received for publication: 29 November 2017. Accepted for publication: 5 July 2018 .

This work is licensed under a Creative Commons Attribution NonCommercial 4.0 License (CC BY-NC 4.0).

CCopyright R.M. Mulenga et al., 2018

Licensee PAGEPress, Italy

Journal of Public Health in Africa 2018; 9:823 doi:10.4081/jphia.2018.823

Transformational, transactional and passive-avoidant (laissez-fare) were the three main leadership styles investigated in this study. Transformational leadership refers to a leader who motivates followers to perform to their full potential over time by influencing a change in perceptions and by providing a sense of direction for the benefit of the organization. ${ }^{6}$ A transactional leader has been defined as a leader or manager who functions in a sense of direction by predefining objectives and goals and uses rewards, punishment to motivate subordinates. ${ }^{6}$ Laisser-faire or Passive avoidant leadership refers to a leadership style where a leader avoids interference, making decision and let events take their own course. Passive-avoidant leadership forces employees to search for a solution by themselves because their leader is often absent if problems occur. ${ }^{6}$ Bass \& Avolio ${ }^{9}$ have suggested that there is a relationship between a manager's leadership style and employee's satisfaction levels and motivation. This relationship is positively associated with patient and organization outcome. ${ }^{10}$

This is summarized in the adopted Pathgoal theory model of leadership influence on healthcare providers and service delivery.

The logic framework model (Figure 1) combines leadership practices and leadership outcome on providers as the first outcome and on service delivery as second outcome from Northouse. ${ }^{11}$ The model suggests that leader's behavior is contingent to 
the satisfaction, motivation, efficiency and extra effort of subordinates that will consequently lead to a particular outcome such as quality and responsive health service delivery. The conceptual framework informed the design and the way the researcher perceived the effects of leadership practices. This was done by first establishing the common leadership practices and then identifies their influence on providers and service delivery. The framework hinges on the type and application of leadership practices as a determining factor in all that follows on health care providers and in health care service delivery pathway.

\section{Materials and Methods}

\section{Study area}

The study was conducted in Lusaka Province-Zambia and comprised of six (6) hospitals that were purposively selected from the $1^{\text {st }}$ level hospitals from public, mission and private.

\section{Sampling}

Data were collected from a total of 42 participants as shown in Table 1 , of which $12 / 42$ (29\%) were leaders and 30/42 (71\%) were healthcare providers. The selection of participants was purposeful and based on their position within the hospital as either hospital administrator and or nursing officer. Convenience sampling of healthcare providers was employed by selecting whoever was found on duty on the material day from among different units of healthcare providers. Healthcare providers were key informants because they experienced the leadership from either hospital administrators and/or nursing officers.

\section{Study design}

The study employed a cross-sectional qualitative design to establish the common leadership practices and determine their influence through 10 health system managers (leaders) and 32 healthcare providers.

\section{Data collection}

The data was obtained using in-depth interviews, focus group discussion, partici- pant observation and document review. All leaders were involved in one to one interview using semi-structured questions and all healthcare providers took part in focus group discussions of 5 members per group and 5 sessions were conducted. This was guided by the interview schedule. In order to strengthened triangulation of participation and also assured the trustworthiness of the research results for this study, participant's observation and document review was employed.

\section{Data analysis}

Data analysis was done by first transcribing audio-recorded interviews and grouping them into data sets (matrixes) where emerging themes were categorized manually. The most frequent words and phrases were underlined and were presented in matrix form for ease cleaning and coding. As suggested by McMillan \& Schumacher, ${ }^{12}$ the manual analysis of data was begun by first transcribing the verbatim counts from the focus group discussions and one to one interview. Then the data segments were formed and coded. The codes were formed from practices in each data set. The grouping of similar codes led to emergent categories. The data collected from participant observation schedule and document review were put in matrix segments as well, and then analyzed by noting the frequency of similar answers which were also coded with themes or categories. For the analysis of data from participant observation and document review, there was open coding, creating categories and abstraction where notes and headings were written in the text while reading them. The written material was read through again, and as many headings as necessary were written down in the margins to describe all aspects of the content. This was informed by Elo \& Kyngäs. ${ }^{13}$ Themes were formed manually based on the most frequently repeated responses from the transcribed audio recorded in-depth interviews as well as repeated noted data from participant observation schedule and document review.

The information obtained assisted in making conclusions and interpretations by providing eminent explanations pointing to specific leadership styles investigated and influence caused on healthcare providers and service delivery.

\section{Results \\ Participants' demographics charac- teristics}

Of the total number of 42 participates, 12 were leaders of which 3/12 (25\%) were males and 9/12 (75\%) were females and of the 30 healthcare providers $13 / 30(43 \%)$ were males and 17/30 (57\%) were females. The results showed that they were more female participants than males from both the leaders and the healthcare providers. The larger proportion for leaders came from the 44-54 years age group whilst the larger proportion for healthcare providers was from the 25-34 years age group. Detailed demographic information of the study sample for both leaders and healthcare

Table 1. Study sites and participants.

\begin{tabular}{|c|c|c|c|c|}
\hline District & Healthcare providers, $\mathbf{n}$. & Hospital administrator, $\mathbf{n}$. & Nursing officer, n. Total, n. & Total, $\%$ \\
\hline Lusaka & 15 & 3 & 21 & 50 \\
\hline Chongwe & 5 & 1 & 7 & 16.6 \\
\hline Rufunsa & 5 & 1 & 1 & 16.6 \\
\hline Chirundu & 5 & 1 & 7 & 16.6 \\
\hline Total & 30 & 6 & 42 & 50.2 \\
\hline
\end{tabular}

Figure 1. Path-Goal theory model of leadership influence on healthcare providers and service delivery.

$\begin{aligned} & \text { Leadership Practices } \\ & \text { Directive(Transactional) }\end{aligned}$
$\begin{aligned} & \text { Epplication of leadership styles and influence on healthcare providers } \\ & \text { Satisfaction, efficiency, motivation, extra effort } \\ & \text { Access, quality care, responsiveness }\end{aligned}$
Derived: Northhouse, (2006)


providers is presented in Table 2

Major and sub-themes emerged in relation to identification of common leadership practices and influence caused on healthcare providers and the effects exerted on service delivery are presented in Table 3 .

\section{Major theme objective 1: common leadership practices}

Leadership was noted as positive and negative practices. The first positive sub- theme was networking explained as effective communication, team work and meetings. Interpersonal relationship was the second sub-theme and was explained as understanding employees, allowing freedom and being interactive. The third positive subtheme leadership practice was Human/material resources management and was explained as resource mobilization/provision, Continuous Professional Development (CPD), Annual Performance
Appraisal System (APAS) and staff involvement. The final positive sub-theme practice was monitoring and evaluation and this was explained as staff monitoring, target setting and guidance. Then the negative sub-themes leadership practices were dictatorial tendencies and overworking of employees. Dictatorial tendencies were explained as favoritism, delayed response, leaders not being exemplary and disrespectfulness. Then overworking of employees

Table 2. Participants' demographics.

\begin{tabular}{|c|c|c|c|}
\hline Demographics & Leaders (12) & Healthcare providers (30) & Total (\%) \\
\hline $\begin{array}{l}\text { Gender } \\
\text { Male } \\
\text { Female }\end{array}$ & $\begin{array}{l}3 \\
9\end{array}$ & $\begin{array}{l}13 \\
17\end{array}$ & $\begin{array}{l}16(38) \\
26(62)\end{array}$ \\
\hline $\begin{array}{l}\text { Age } \\
\begin{array}{r}18-24 \\
25-34 \\
35-44 \\
44-54 \\
55-64\end{array} \\
\end{array}$ & $\begin{array}{l}- \\
3 \\
2 \\
5 \\
2\end{array}$ & $\begin{array}{c}1 \\
20 \\
5 \\
2 \\
2\end{array}$ & $\begin{array}{c}1(1) \\
23(55) \\
7(17) \\
7(17) \\
4(10)\end{array}$ \\
\hline $\begin{array}{l}\text { Race } \\
\text { European } \\
\text { African } \\
\text { Mixed race } \\
\text { Others }\end{array}$ & $\begin{array}{c}1 \\
10 \\
- \\
1\end{array}$ & $\begin{array}{c}- \\
30 \\
- \\
-\end{array}$ & $\begin{array}{c}1(2.4) \\
40(95) \\
- \\
1(2.4)\end{array}$ \\
\hline $\begin{array}{l}\text { Education Level } \\
\text { Certificate } \\
\text { Diploma } \\
\text { Degree } \\
\text { Post-graduate } \\
\end{array}$ & $\begin{array}{l}- \\
6 \\
4 \\
2\end{array}$ & $\begin{array}{c}4 \\
21 \\
5 \\
-\end{array}$ & $\begin{array}{c}4(10) \\
27(64) \\
9(21) \\
2(5)\end{array}$ \\
\hline 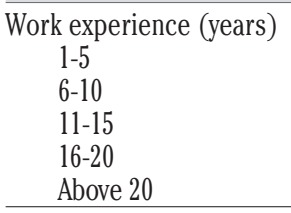 & $\begin{array}{l}2 \\
3 \\
4 \\
2 \\
1\end{array}$ & $\begin{array}{c}9 \\
13 \\
5 \\
3 \\
-\end{array}$ & $\begin{array}{c}11(26.2) \\
16(38.1) \\
9(21.4) \\
5(12) \\
1(2.3)\end{array}$ \\
\hline
\end{tabular}

Table 3. Major and sub-themes.

\begin{tabular}{|c|c|c|}
\hline \multicolumn{3}{|c|}{ Common Leadership Practices } \\
\hline Positive & $\begin{array}{l}\text { Networking } \\
\text { Interpersonal relationships } \\
\text { Human/Material resources management } \\
\text { Monitoring and Evaluation }\end{array}$ & $\begin{array}{l}\text { Effective communication; Team work; Meetings } \\
\text { Understanding staff; Allowing freedom; Being interactive; Leading by example } \\
\text { Resource mobilization/provision; Continuous professional development; } \\
\text { Annual performance appraisal system; Staff involvement } \\
\text { Monitoring; Target setting; Guidance }\end{array}$ \\
\hline Negative & $\begin{array}{l}\text { Dictatorial tendencies } \\
\text { Overworking employees }\end{array}$ & $\begin{array}{l}\text { Favoritism; Delayed response; Not exemplary; Disrespectfulness } \\
\text { Selfishness; Absence of leaders }\end{array}$ \\
\hline \multicolumn{3}{|c|}{ Types of influence enhanced by the practices } \\
\hline Positive & $\begin{array}{l}\text { Confidence } \\
\text { Motivation for hard work }\end{array}$ & $\begin{array}{l}\text { Pay attention to duty; Work with a free mind; Makes them aware of their } \\
\text { weakness/strength; Providers do they work well } \\
\text { Encouragement; Shared solution; Clear direction }\end{array}$ \\
\hline Negative & $\begin{array}{l}\text { Compromised quality of work } \\
\text { De-motivators }\end{array}$ & $\begin{array}{l}\text { Tiredness; Lack of concentration at work } \\
\text { Disappointments; Conflicts; Safety and security; Unfair treatment }\end{array}$ \\
\hline
\end{tabular}

Direct (positive) effects High quality performance

Indirect (negative) effects Poor performance
Avoiding mistakes; Togetherness and enhanced providers happiness; Increased providers confidence; Respect for clients; Independent mind Compromised quality of care; Relaxes when carrying out tasks; Moving up and down instead of working; Offering of outdated services; Carrying out tasks carelessly; Working in fear 
was explained as Selfishness and absence of leaders.

\section{Positive common leadership practices: Networking communication}

Communication was found to be important by both leaders and providers in ensuring that tasks were performed accordingly and errors avoided.

Leader 7 at hospital 4 said that: "We do notify the staff of new policies or guidelines received from the Ministry, we also make sure that department are speaking to each other on the noted problem, it can be clinical, administrative or human resource issue and we take they suggestions...."

\section{Interpersonal relationship: Being interac- tive}

When leaders interact with the providers they felt valued and considered. This practice made healthcare providers approach the leaders without fear and got satisfied. In hospital 3, provider respondent 14 said that: "I like the interaction, these are people who come down to our level and I feel good to discuss with my supervisor".

\section{Human/material resources management: Resource mobilization and provision}

Providing resources to providers was frequently mentioned by all the leaders and the providers and noted in documents which were reviewed (i.e. the files for top management meeting minutes, quality Assurance Assessment report and Quarterly Performance Assessment reports). Alluding to this fact leader 2 at hospital 2 said that: "We try our best to ensure that the items that they need to conduct the services and perform better are available, these we provide whenever they need in the department".

\section{Monitoring and evaluation: Monitoring}

This leadership practice was mentioned in all the 6 hospitals by all the leaders. The providers mentioned this practice in 4 hospitals. In documents reviewed it was found recorded. This suggests that it is mostly done practically. In the participant observations, monitoring was seen to be done by leaders walking around the wards, departments and other units to check what was happening.

Leader 10 in hospital 5 said: "Every morning, I go around to check each and every department to check what they are doing to make sure things are there, everything is there, staff is there........."

\section{Guidance}

The findings on this practice were that the practice of giving guidance to healthcare providers corrects their mistakes and clears the direction in their operations. This practice lessens mistakes and the resentment that can stem from feeling 'ordered around'. Healthcare providers felt that their leaders recognized their services and they tried to transform them by guidance. One of the healthcare providers, respondent number 28 at hospital 6 guidance said that: "The leaders are attentive, listen to our views and guide us and give direction where it is necessary, this helps to avoid mistakes."

\section{Negative common leadership practices: \\ Dictatorial tendencies}

Leaders registered to have been practicing dictatorial leadership in all the 6 hospitals and it was also noted under participant observation.

Leader 7 in hospital 4 in her statement said; "They say I am too strict because I don't play with issues; I want work to be done in the right way... I don't change my opinion if someone proposes an opinion against the vision, I just say NO and it is a NO".

\section{Disrespectfulness}

The findings here were that when leaders in hospitals act in a disrespectful manner towards the healthcare providers, they make them feel embarrassed and disappointed. The healthcare providers registered their leaders of not giving them the respect they deserve as respondent number 2 , in hospital 1, alluding to this influence narrated that: "At times we are treated like children, at one time the samples we took delayed to be ready, we were so disappointed, when the leader shouted at us in the presence of patients".

\section{Overworking employees}

This negative practice was registered by both the healthcare providers and leaders. Leaders attributed this fact to staff shortages. The findings here were that when health care providers are overloaded, they get overwhelmed, tired and end up frustrated. Alluding to this fact provider 8 in hospital 2 said that;

“....You get too tired because you do a lot of things, just like you saw in other departments, you are overwhelmed, and you are just alone, you get frustrated you don't rest at all".

\section{Major theme objective 2: Types of influence enhanced by the leader- ship practices on healthcare providers}

Leadership practices noted enhances a positive or negative attitude in providers. Positive influence included confidence as the first sub-theme and it was associated with paying attention to duty, working with a free mind, making providers aware of their weakness and strength. The second positive sub-theme was motivation which was associated with encouragement, shared vision and a clear direction.

Healthcare providers felt cared for and also applied the same care to patients when such positive leadership practices are upheld. Respondent number 18 at hospital 4 alluding to such positive practices said that: "They try to motivate us by coming to the ward to see what we are doing and advise us, they (leaders) pass through to see that everything is well. They show care and so we also show care on our patients too".

Negative influence on provider's attitudes was registered as compromised quality of work and was associated with tiredness, lack of concentration and de-motivators which was associated with disappointments, conflicts, unfair treatment, safety and security.

The negative influence on providers discouraged their hard work. One provider respondent 21 in hospital 5 stated that: "There is too much intimidation...we are told only what has been decided, no way you can be involved, they know you cannot complain anywhere, I feel performance is going down".

The findings showed that dictatorial tendencies disturb healthcare providers in their performance. It causes conflicts between the written rules and what leaders do towards the providers. This discourages their hard work.

\section{The ways in which the practice of communication influences healthcare providers}

The findings show that providers do their work well when communication flows from them to leaders and leaders respond to their needs. One of the health care providers, respondent number 26 at hospital 6 when asked about the practice that he liked in her leaders said: "The leader does not just do what she wants, but she asks us what we want every day and we tell them and this encourages us". When providers are communicated to it increases confidence and they get motivated.

\section{The ways in which the practice of team work influences delivery of healthcare providers}

Teamwork in hospitals motivates the health care providers. They feel encouraged especially when it involves their leaders teaming up with them in what they are doing in their service delivery. One health care provider respondent number 6 in hospital 2 when asked on the leadership practice they liked in their leaders said: "I get encouraged because if, for example, I have 
to do incision and drainage (I\&D) and then I am uncomfortable, I ask for the leaders, they come and we do it together".

Team work helps the healthcare providers carry out well coordinated services and they feel encouraged through a shared vision and clear direction.

The ways in which the practice of understanding situations influence healthcare providers

According to the above findings, the way in which the leaders practice understanding their employees' situation also directly impacts on the healthcare providers. This is so when they see that leaders quite understand by way of the response they give to their situations, they get motivated to work even harder. Leaders are expected to understand the expressed and unexpressed need of their providers and make them feel at ease. Leaders are appreciated when they listen and understand their provider's problems.

This is attested by one provider respondent number 19 at hospital 4 who said that: "They quite understand...sometimes if you have a sick child at home and you phone them, they even come to visit the sick child. This motivates us and you put in your level best because you feel loved and cared for".

The ways in which the practice of providing the required resources influences healthcare providers

This practice where leaders supply all the required resources to the providers exerted a positive influence on the providers. It makes the providers of health care services happy and enjoys their work when the resources are supplied. One healthcare provider, respondent number 28 in hospital 6 said: "Whenever we ask for things or when we suggest something that we need in our department, they (leaders) always make these things available, they always deliver and we are happy".

The ways in which the practice of monitoring influences healthcare providers

The findings here showed that when leaders in hospitals monitor the health care providers as they do their work, it makes them to pay much attention to what they are doing because they see their leaders care on how they are working by passing through to check how they are doing their work. One health provider (respondent number 22 from hospital 5) alluded to this fact that: "They check on us, how you are performing the work, they make you behave in a certain way, they have put CCTV everywhere to check what you are doing. We spend $90 \%$ of time working and being monitored".
The ways in which the practice of guidance influences healthcare providers

From the verbatim count, it is clear then that when healthcare providers have a problem and leaders note it and take time to explain what to do to correct that mistake, the provider straight away change in the way they do the task which was problematic. When mistakes are corrected it gives clear direction on operation as alluded by one provider responded number 20 at hospital 4 who said that: "We are corrected whenever we go wrong and when mistakes are noted we are called in the office to discuss and usually there is privacy".

\section{Negative influence of leadership practices on healthcare providers}

\section{Influence of dictatorial tendencies on healthcare providers}

Negative influence on provider's attitudes was registered as compromised quality of work and de-motivators. Compromised quality of care was associated with tiredness as well as lack of concentration at work whist de-motivators was associated with disappointment, conflicts, unfair treatment, safety and security.

The negative influence on providers discouraged their hard work. One provider respondent 21 in hospital 5 stated that: "There is too much intimidation...we are told only what has been decided, no way you can be involved, they know you cannot complain anywhere, I feel performance is going down".

The findings showed that dictatorial tendencies disturb healthcare providers in their performance. It causes conflicts between the written rules and what leaders do towards the providers. This discourages their hard work.

As stated above on the types of influences that dictatorial tendencies exert on providers, it is clear that the way in which this practice of being dictatorial in the leadership approaches towards healthcare providers is that causing fear in the providers.

One provider respondent number 25 in hospital 5 went on saying: "Our supervisors influence us negatively because even when there is shortage of man power and we are overwhelmed, you cannot complain anywhere".

\section{Influence of favoritism on healthcare providers}

The findings on this practice were that it influences the healthcare provider's operation in the negative way. Mostly this practice was noticed in leaders when it came to the aspect of choosing who to send to workshops and who to go on leave. One health- care provider respondent 9 at hospital 2 said that: "Some of us we just work we are not involved like workshops, they always choose the same people so we feel discouraged, if you are not like yes 'bwana' every time you are not favored".

\section{Influence of disrespectfulness on health- care providers}

The findings here were that when leaders in hospitals act in disrespectful manner towards the healthcare providers, they influence them negatively in that they make them feel embarrassed and disappointed as stated by one provider respondent number 22 at hospital 5 who complaint that: "You may have a point to explain but they will shout at you, it frustrates".

The findings above indicate or show that when healthcare providers are not respected in the way they are handled by their leaders, they get disturbed due to embarrassment and frustration that result.

\section{Influence of selfishness on healthcare providers}

Another provider number 2 at hospital 1 said that: "Each department has rules and regulations but here there is that conflict when the leader wants this to be done in that way, it has to be done regardless of the rules in that department on samples taken".

\section{Influence of work overload on healthcare provider}

From the verbatim counts of the providers, in hospital 2 above, it can be deduced that the way of influence where providers are overloaded is a direct way. When health care providers are overworked, there and then they become frustrated due to fatigue. Provider, respondent 4, at hospital 1 said that: "When it gets too much of work, they say no, come back even when you have knocked off. You feel commanded and unfairly treated. So instead of you feeling sorry for the patients you lie, you are like anyway let me just stop now, you just get frustrated".

When they are called back it inconveniences them and just go back annoyed and start doing own things.

\section{Major theme objective 3: The ways in which the identified leadership practices affects the delivery of health care services}

This was registered as direct (positive) and indirect (negative) effects on healthcare delivery services. The direct or positive effect of leadership practice on service delivery was 'high quality performance' which included 'avoiding mistakes, togetherness and enhanced providers happiness, 
increased providers confidence, respect for clients and work with an independent mind'. Then the indirect or negative effect of leadership practice on service delivery was 'poor performance' which included compromised quality of care, relaxing when carrying out tasks, moving up and down instead of working, offering of outdated services, carrying out tasks carelessly and working in fear.

\section{Direct effects or influence of leadership practices on service delivery.}

The findings from the providers as can be seen from the quotes are that, target setting when practiced by the leaders on health care providers directly affects their operations by way of alerting them to the expected performance achievements. This practice further motivates providers for hard work as eluded by provider, respondent number 26 in hospital 6 who said: "Our leaders give bench marks and you are given a period in which to achieve the assignment. This affects the way we perform, we work hard to achieve goals".

\section{Effects of communication on service delivery}

The practice of allowing communication to flow between healthcare providers and their leaders in hospitals directly influences the health care delivery services. It gives them joy and helps them plan their work effectively as can be seen from the verbatim quote above and as provider, respondent number17 at hospital 4 said: "There is good communication... before you came here I was told that you will be coming, it helps to plan well and be ready".

\section{Effects of resource provision on influence service delivery}

The ways in which this practice affects the delivery of health care provision is direct. When leaders supply needed items for services, providers become happy to do their work. One provider, respondent number 25 in hospital 5 had this to say: "Our leaders tell us to use all the materials we order and not to order something that is not going to be on the shelf or be seen on the shelf for a long time, this supports us very much."

\section{Effects of disrespectfulness on service delivery}

The ways in which disrespect influence providers is somehow direct because when the leader shout at the providers they go away and expected work to be done. But the provider interviewed said this frustrated them. One of them quoted in hospital 2, respondent number 10 , gave an example of instances where the leaders (doctor) shouted at her: "Patient came at 8hrs and I felt the urgent need for him to be seen by the doctor and started following the doctor, until 15hours then he started shouting at me saying why are you following me, has the patient paid you? Then you start to plead, if you do not plead, you will be following them everywhere and this affects performance".

\section{Effects of workload on service delivery}

The finding on the practice of work overload has a negative influence on quality of service delivery.

Provider number 10, at hospital 2 attesting to this said that;

"It's too much, these people overwork us, you knock off at 17 hrs then they call you back, they send the driver to pick you and driver refuses to take you back. You are in the hospital till 20hrs and you will have to look for transport to go back, so on that part instead of feeling sorry for these patients you go like let me just close."

This remark showed that the effects of overloading providers is direct and it caused stoppages of work even when a provider is present. This type of influence exerted by the practice of overloading of employees with tasks is negative.

\section{Indirect effects or influence on serv- ice delivery}

\section{Effects of monitoring on service delivery}

The way in which this practice influences the providers is indirect because when leaders monitor their healthcare provider's performance, providers feel cared for and also feel motivated. It happens that when leaders monitor their healthcare provider's performance by walking around, (management by walking around) the healthcare providers jack up and see to it that they are doing their delivery of healthcare services well. Healthcare providers feel cared for and also apply the same care to patients as provider, respondent number 18 at hospital 4 alluding to this practice in this hospital said: "They try to motivate us by coming to the ward to see what we are doing and advise us, they (leaders) pass through to see that everything is well. They show care and so we also show care on our patients too."

\section{Effects of understanding providers on service delivery}

When leaders show understanding of their employee's situations they are indirectly motivated to work hard. Respondent number 24 a provider form hospital 5 said that: "If I have a problem immediately I talk to the manager so that way this contribute to delivery of quality health services because they will understand me and solve the problem and that way I will continue working well then if they don't understand the situation".

\section{Effects of monitoring providers on service delivery}

The way in which this practice influences the providers is indirect because when leaders monitor their healthcare provider's performance, providers feel cared for and also feel motivated. It happens that when leaders monitor their healthcare provider's performance by walking around, (management by walking around) the healthcare providers jack up and see to it that they are doing their delivery of healthcare services well. Healthcare providers feel cared for and also apply the same care to patients as provider, respondent number 18 at hospital 4 alluding to this practice in this hospital said: "They try to motivate us by coming to the ward to see what we are doing and advise us, they (leaders) pass through to see that everything is well. They show care and so we also show care on our patients too".

\section{Effects of dictatorial tendencies on service delivery}

The statements above may mean that if you can't make the leaders stop practicing dictatorship, start dictatorship as well. And since the providers cannot be dictatorial to their leaders, they possibly exert the similar practice on the patients which is a kind of projection of anger to innocent patients. Therefore, if not motivated, there is less performance and has a negative impact on services offered by the providers. This is attested by one provider respondent number 9 at hospital 2 who said that: "There is too much too dictatorship, they always will tell you what you should do without even asking how your department is that day and sometimes you knock off late and again at night they call you, how can you perform it is frustrating".

\section{Effects of selfishness on service delivery}

This practice affects the providers and service delivery indirectly, when the providers are forced to do what is not right they felt insecure and do tasks carelessly and ineffectively as alluded by provider number 12, at hospital 3 that: "There is always that aspect of moving away from the regulations...but you are scared to refuse, so I work so that I am not the topic of discussion".

Another provider 16, at hospital 4 said: "As professionals we want to perform professionally, but if a leader wants to do 
things in the way he wants, I feel I am being hindered, there are times whereby we ran reports in the way they want not what the profession says, so we are hindered to report facts...time to be ready and this delay results but without asking and ignoring what goes on he started shouting at us, we felt very discouraged and disappointed".

\section{Discussions}

The study showed that the two common leadership practices were transformational and transactional. This was noted from leaders and providers on identification of their preferred and experienced leadership styles that were pointing to these two leadership styles. This wide choice was not a mere coincidence but indicated a natural trend in the practice which most leaders in $1^{\text {st }}$ level hospitals employ. It is an indication of a trend where hospitals are not stagnant in their operations but are very progressive. These findings are similar to studies done by other authors, $4,10,14$ who showed the highest score received by the transformational style of leadership followed by transactional leadership and the least was lasseiz-fare style of leadership. It is also an indication that leadership in hospitals is shifting from transactional to transformational leadership culture, the one that is more collaborative Whereas transactional leadership involves a leader predefining objective and goals and uses rewards and punishment to motivate subordinates, transformational leaders uplift morale, motivation and morals of subordinates.

The transformational leadership practices were evidenced through resource provision, holding of meetings, enhancing professional development, appraising staff, targets setting, involving staff in management activities, guidance, monitoring, understanding staff, allowing freedom, leaders interacting with staff and leaders being always available. These practices were noted to motivate, satisfy and made healthcare providers carry out their work efficiently and put in some extra effort. This agrees with the studies done by other authors, ${ }^{14,15}$ who indicated that attributes and behaviors such as identifying qualification needs, professional development and other needs and aspiration of followers were associated with a transformational leader.

Under the practice of resource provision, the findings showed that supplying the providers of healthcare with the required materials makes health care provision to be well delivered. This is so especially when it is accompanied by the instruction to see to it that the supplied materials are not left unused. Since this practice makes the providers of health care happy as they do their work, it directly motivates them to offer the services to patients in a better way, ${ }^{16}$ indicated that resource provision such as essential medicines and supplies and equipment are deemed as core inputs and very necessary for effective health care delivery services. These inputs must be available and accessible for providers in order to have an impact on health outcome.

Under the practice of monitoring, it is clear from the findings confirmed by verbatim counts from the previous chapter that the practice of walking around to see how healthcare providers are delivering their health care services caused them to deliver these services well. This is supported by the notion "a good principal monitors implementation". ${ }^{17}$ In this way then, management by walking around (MBWA) is an effective practice towards the enhancement of effective health care delivery. The opposite could be the case where such a practice is not done. Monitoring employees is one way in which a leader can ensure that the tasks are well done. This leadership practice requires commitment and strategic thinking so that it is maximized in a way that does not frustrate those being monitored.

The other common leadership practice preferred and perceived or experienced was transactional style of leadership, commanding leadership practice characterized by an emphasis on compliance and control and leading through power. This indicates that power and authority prevailed in this leadership practice and this contextualizes the practices in the light of call to dictatorial governance. This is similar with the findings by Morsiani et al. ${ }^{18}$ who noted transactional leadership as main leadership style where doctors, managers, senior nursescontrolled nurses through power and authority ascribed to their roles. They further indicated that new practitioners felt demoralized and undervalued and work environment was found to be stressful and full of conflicts.

Therefore, the relationship among leaders and followers in this type of leadership style is based on the principal of returning rewards or incentives in response to appreciable performance of employees. ${ }^{19}$ In this study healthcare providers did not perceive transactional leadership style as a good practice to be practiced by their leaders because it did not encourage them. This is consistent with the findings by Voon et al. ${ }^{20}$ who indicated that transactional leadership had a negative relationship with emploees' job satisfaction.

This type of leadership practice was fur- ther through dictatorial tendencies, favoritism, selfishness, and absence of leaders, disrespectfulness, being overworked and delayed response.

Leaders could ask for employee's opinion on certain issues, but usually they have made decisions and this was not changed by the opinion of employees. When one leader indicated that she does not play with issues and that she does not change her opinion in one of the verbatim accounts, it is a clear indication of dictatorial practice that does not give room for employee's consensus. When leaders order what has to be done and keep tract of mistakes, it disturbs their performance and discourages and demoralizes their hard work.

Overall, the assumptions of the pathgoal theoretical framework were supported by the results.

\section{Conclusions}

The common leadership styles preferred and perceived or experienced in first level hospitals in Lusaka Province was the transformational type of leadership followed by transactional leadership as attested by the practices from the leaders and experiences from the healthcare providers.

Leadership styles affect employees' commitment, motivation, satisfaction, extra effort and efficiency. This in turn has a bearing on performance and directly or indirectly influences patient care and its quality. Health system managers have a significant role in using leadership styles that promote good practice.

It can be safely concluded that hospital performance and quality health care delivery services is a product of several factors. The analysis of leadership practices in this study shows two of the factors influencing hospital performance. The first factor is the effectiveness of leaders within the hospital to include hospital administrators and nursing officers in supporting the healthcare providers as well as conveying the organization values, mission and culture by adopting good leadership practices. Secondly it is the dedication, motivation, commitment and performance of employees that will improve health care services. This study has contributed relatively to the scanty body of work on leadership and its influence on providers and service delivery in middleand low-income settings.

\section{Recommendation}

Policy makers in health care organization must ensure that leadership and management training programs for health system managers are promoted and encouraged 
to improve leader's self-reflection through which they are better able to vary their leadership style.

\section{Limitation}

The sample size was too small and only selected in one Province of Zambia, therefore it does not represent the entire Zambian healthcare providers limiting the generalization of results.

\section{References}

1. Mutale W, Mutale ATV, Kachemba A, et al. Leadership and training as a catalyst to health system strentheing in low income settings: Evidence from implemetation of Zambia Management and Leadership course in Zambia. PLoS One 2017;12:e174536.

2. Gilson L, Daire J. Leadership and Governance within the South African Health System. South Afr Health Rev 2011;69-80.

3. Frank B, Eckrich H, Rohr J. Quality nursing care leadership makes the difference. J Nurs Admin 1997;27:13-4.

4. Chiok Foong Loke J. Leadership behaviours: Effects on job satisfaction, productivity and organizational commitment. J Nurs Manag 2001;9:191-204.

5. Schreuder J, Roelen C, Zweeden N, et al. Leadership effectiveness and recorded sickness absence among nursing staff: a cross-sectional pilot study. J
Nurs Manag 2011;19:585-95.

6. Huber D. Leadership and Nursing Care Management. Amsterdam: Elsevier Health Sciences; 2013.

7. Abdelhafiz IM, Mah'd Alloubani A, Klaledeh M, et al. Impact of leadership styles among head nurses on level of job satisfaction among staff nurses. Eur Sci J 2015;10:11.

8. Deshpande A, Hills C. Leadership styles: A case of Two Hospitals in the US 2011. Available from: https://www.scribd.com/document/282 599203/Leadership-Styles-a-Case-ofTwo-Hospitals-in-the-US

9. Bass BM, Avolio BJ. Improving organizational effectiveness through transformational leadership. Thousand Oaks: Sage; 1985.

10. Abdelhafiz IM, Alloubani AMD, Almatari M. Impact of leadership styles adopted by head nurses on job satisfaction: A Comparative study between governmental and private hospitals in Jordan. J Nurs Manag 2015;24:384-92.

11. Northouse PG. Introduction to leadership: concepts and practice: concepts and practice. Thousand Oaks: Sage; 2014.

12. McMillan JH, Schumacher S. Research in education: Evidence-based inquiry (7th ed.). New Jersey: Pearson; 2006

13. Elo S, Kyngäs H. The Qualitative content analysis process. J Adv Nurs 2008;62:107-15.

14. Alloubani AM, Almatari M, Almukhtar
M. Review: Effects of Leadership Styles on Quality of Services in Healthcare. Eur Sci J 2014;10:118-29.

15. Miia M, Nicole H, Karlos A, et al. Project-based management as an organizational innovation: Drivers, changes, and benefits of adopting project-based management. Project Manag J 2006;37:87-96.

16. Islam M. Health Systems Assessment Approach: A How-To Manual. Health Systems Assessment Approach: A HowTo Manual 2007.

17. Zambia-Ministry of Education. Providing equitable and accessible education and skills growing opportunity for sustainable livelihood and development, infrastructure operation plan. 2008.

18. Morsiani G, Bagnasco A, Saaso L. How nurses staff nurses perceive the impact of nurse managers' leadership style in terms of job satisfaction: a mixed study. J Nurs Manag 2017;25;119-28.

19. Bass BM, Avolio BJ. Transformational leadership: A response to critiques. In: Chemers M, Ayman R, Eds. Leadership theory and research: Perspectives and directions. New York: Academic Press; 1993. pp. 49-80.

20. Voon ML, Lo MC, Ngui KS, Ayob NB. The inflence of leadership style on employees job satisfaction in public sector organisations in Malaysia. Int $\mathrm{J}$ Business Manag Soc Sci 2011;2:24-32. 